\title{
LATAR BELAKANG PEMIKIRAN DAN KIPRAH SEYYED HOSSEIN NASR
}

\author{
Titin Nurhidayati \\ Fakultas Tarbiyah IAI Al-Falah As-Sunniyyah Kencong \\ Titinnurhidayati77@gmail.com
}

\begin{abstract}
Seyyed Hossein Nasr is one of the Muslims who has expertise in the field of Islamic studies that penetrates scientific barriers to explore Islam as an objective and honest study. His reputation as Professor in the study of the history of science and philosophy shows the depth and sharpness of his thinking. Seyyed Hossein Nasr gave many criticisms of the reality of modern humans today from various aspects. One focus of his criticism is the problem of the phenomenon of modern art which is developing rapidly to all parts of society, including Islamic society. Nasr is also one of the spokespersons of Islam in the West who has been persistent in voicing traditionalism ideas to fortify the flow of modernization that has damaged the joints of the noble traditions of society, especially Islam.
\end{abstract}

Keywords: Portrait of Life, Background of Thought and Gait Nasr

\begin{abstract}
Abstrak
Seyyed Hossein Nasr adalah salah seorang diantara muslim yang mempunyai keahlian dalam bidang kajian Islam yang menembus hambatan-hambatan ilmiah untuk menggali islam sebagai pengkajian secara objektif dan jujur. Reputasinya sebagai Guru Besar dalam kajian sejarah ilmu pengetahuan dan filsafat menunjukkan kedalaman dan ketajaman pemikirannya. Seyyed Hossein Nasr banyak memberikan kritik atas kenyataan manusia modern saat ini dari berbagai segi. Salah satu fokus kritiknya adalah masalah fenomena seni modern yang sedang berkembang pesat ke seluruh bagian masyarakat, termasuk masyarakat Islam. Nasr juga merupakan salah satu juru bicara Islam di Barat yang gigih menyuarakan pemikiran Tradisionalisme untuk membentengi arus modernisasi yang telah merusak sendi-sendi tradisi luhur masyarakat khususnya Islam.
\end{abstract}

Kata Kunci: Potret Kehidupan, Latar Belakang Pemikiran dan Kiprah Nasr 


\section{Titin Nur Hidayati}

\section{PENDAHULUAN}

Dominasi yang terjadi dalam pola pikir masyarakat modern adalah model positivistik yang menggunakan ukuran sebuah kebenaran menggunakan kacamata pengetahuan empiris dan rasional. Positivisme akan menolak cara orang lama berfikir, di mana pengalaman yang sehari-hari dan perasaan religius saling meresapi, dan agama merupakan penafsiran dan pengertian yang benar ${ }^{1}$. Yang nyata adalah yang material. Nilai-nilai dan pengetahuan yang bersifat material tumbuh pesat jauh melampaui hal-hal yang bersifat spiritual, sehingga masyarakat kehilangan keseimbangan.

Kenyataan di atas tidak dapat terelakkan juga berdampak pada dunia seni atau estetika. Masuknya pandangan sekuler ke dalam dunia seni selain menambah beraneka ragamnya hasil kreasi seniman, juga berdampak buruk terhadap eksistensi seni itu sendiri ${ }^{2}$. Seni yang seharusnya sarat dengan makna-makna spiritual, mengemban pesan yang tinggi dengan media manifestasi masing-masing, menjadi tergradasi dan gersang makna. Yang ada hanyalah seni untuk seni yang hanya memburu kebebasan material ekspresi dengan mengabaikan substansi makna dan pesan moral yang tinggi dalam ekspresi itu.

Pandangan ini muncul abad 18 dalam khazanah filsafat seni Eropa dengan istilah disini terestednes atau tanpa kepentingan Yang dimaksud dengan tanpa kepentingan adalah bahwa karya seni itu bebas dari kungkungan ruang dan waktu tertentu, atau konteks dan pengaruh tertentu, sehingga karya seni menemukan nilai universalnya melampaui batas-batas yang ada dan abadi.

Telah banyak karya seni modern yang melukis dengan media badan dengan kebebasannya tanpa menghiraukan norma-norma dan etika yang ada, menjadi tren yang mengkhawatirkan. Alasan melakukan hal tersebut adalah kebebasan berekspresi. Akan tetapi tanpa dasar spiritual yang dilandasi intelektual yang jelas. Hal ini tidak dapat dihindari berdampak terhadap masyarakat Islam. Sumber spiritual Islam dari Al-Qur'an dan Sunnah telah banyak terlupakan. Para seniman cenderung sekuler melakukan ekspresi

\footnotetext{
${ }^{1}$ Loren Bagus, Kamus Filsafat, (Jakarta: Gramedia, 2000), 858.

2 Haedar Nashir, Agama dan Krisis Kemanusiaan Modern, (Yogyakarta: Pustaka Pelajar,1999), 4.
}

Falasifa, Vol. 10 Nomor 2 September 2019| 133 
estetisnya $^{3}$.

Dalam kaitannya dengan kenyataan di atas, hadir seorang pemikir kontemporer bernama Seyyed Hossein Nasr banyak memberikan kritik atas kenyataan manusia modern saat ini dari berbagai segi. Salah satu fokus kritiknya adalah masalah fenomena seni modern yang sedang berkembang pesat ke seluruh bagian masyarakat, termasuk masyarakat Islam ${ }^{4}$.

Seyyed Hossein Nasr merupakan salah satu juru bicara Islam di Barat yang gigih menyuarakan pemikiran Tradisionalisme untuk membentengi arus modernisasi yang telah merusak sendi-sendi tradisi luhur masyarakat khususnya Islam. Sekularisasi seni saat ini juga dirasakan masyarakat Indonesia dengan berbagai fenomena bahwa seni tidak lagi mempunyai pesan dari Dunia atas, melainkan hanya sebagai bahan hiburan yang temporal dan terkadang sebagai barang dagangan murahan tanpa memperhatikan tujuan seni sebagai medium antara materialisme dunia dan kerohanian yang kekal.

\section{POTRET KEHIDUPAN SEYYED HOSSEIN NASR}

Seyyed Hossein Nasr lahir pada tanggal 7 april 1933, di kota Teheran, Iran, Negara tempat lahirnya para sufi, filosofi, ilmuwan dan penyair muslim terkemuka. Ayahnya, Seyyed Waliullah Nasr, disamping dikenal sebagai seorang ulama terkenal di Iran pada masanya, juga dikenal sebagai seorang dokter dan pendidik pada masa berkuasanya Reza Shah, ia diangkat setingkat dengan jabatan Menteri Pendidikan (untuk masa sekarang). ${ }^{5}$

Pendidikan dasarnya disamping diperoleh secara informal dari keluarga juga mendapat pendidikan tradisional secara formal di Teheran. Di lembaga ini, ia mendapatkan pelajaran menghafal Al-Qur'an dan menghafal syair-syair Persia klasik. Pelajaran ini sangat membekas dalam jiwa dan pikiran Nasr. Kemudian ayahnya mengirim belajar kepda sejumlah ulama besar di Qum Iran, termasuk kepada Thabathaba'i, penulis tafsir Mizan, untuk mendalami filsafat, ilmu kalam dan tasawuf. ${ }^{6}$

\footnotetext{
${ }^{3}$ Jakob Sumardjo, Filsafat Seni, (Bandung: Penerbit ITB, 2000), 47.

4 Ali Maksum, Tasawuf Sebagai Pembebasan Manusia Modern: Telaah Signifikansi Konsep Tradisionalisme Seyyed Hossein Nasr, (Yogyakarta: Pustaka Pelajar, 2003), 23.

${ }^{5}$ Ali Maksum, Tasawuf Sebagai Pembebasan Manusia Modern, 35-36.

${ }^{6}$ Zainul Hasan, Islam Tradisional; Kajian atas Pemikiran Nasr. (Pamekasan: Journal Studi Keislaman, Vol. V No. 1 STAIN Pamekasan, 2004), 342.

Falasifa, Vol. 10 Nomor 2 September 2019| 134
} 


\section{Titin Nur Hidayati}

Pendidikan tingginya ditempuh di Amerika di Massachusetts Institut of Technologi (MIT), disana berhasil mendaptkan diploma B.S. (Bachelor of Science) dan M.A. (Master of Art) dalam bidang fisika. Prsetasi yang disandangnya belum memuaskan dirinya. Lalu Seyyed Hossein Nasr melanjutkan Universitas Harvard menekuni History of Science and Philosophy, diperguruan tinggi ini Nasr berhasil memperoleh gelar Ph.D (Doctor of Philosophy) pada tahun $1958 .^{7}$

Seyyed Hossein Nasr adalah salah seorang diantara muslim yang mempunyai keahlian dalam bidang kajian Islam yang menembus hambatan-hambatan ilmiah untuk menggali islam sebagai pengkajian secara objektif dan jujur. Reputasinya sebagai Guru Besar dalam kajian sejarah ilmu pengetahuan dan filsafat menunjukkan kedalaman dan ketajaman pemikirannya. Nasr juga ilmuwan muslim yang melanjutkan kritik sedemikian hebatnya. Kepada dunia barat dan peradaban modern pada umumnya, dengan menggunakan pedang intelektualnya.

Sebagai ilmuwan yang sekarang hidup dalam status "setengah pengasingan" karena dahulu bersedia bekerja sama dengan Shah Reza Pahlevi di Teheran dalam mendirikan dan kemudian memimpin sebuah Istitut pengkajian filsafat dan menerima gelar kebangsaan dari sang raja di raja itu. Reputasi Nasr tidak menurun hanya saja Nasr meninggalkan Iran dan menetap disalah sebuah Universitas Amerika Serikat. Selama ilmluwan tidak menjual pengetahuan yang dimilikinya untuk melenyapkan, mengaburkan atau menutupi kebenaran, selama itu pula integritas ilmunya tidak terganggu sama sekali. ${ }^{8}$

Pemikiran Nasr sangat komplek dan multidimensi. Ini dapat dilihat dari karya-karya tulisnya yang membahas berbagai topic mulai dari persoalan manusia modern. Sains, ilmu pengetahuan, seni sampai kepada sufisme. Mengingat kompleksitas pemikiranya, harus di akui, agak sulit memasukkan Nasr ke dalam berbagai tipologi yang pernha dibuat oleh beberapa ahli.

Sebagian orang mungkin akan menggolongkan Nasr sebagai neo-modernis mengingat kepeduliannya kepada konformitas islam dengan dunia modern; apalagi ia

${ }^{7}$ Komaruddin Hidayat, Upaya Pembebasan Manusia Sufistik Terhadap Manusia Modern Menurut Seyyed Hossein Nasr, dalam Insan Kamil: Konsep Manusia Menurut Islam, Penyunting: M. Dawam Rahardjo, (jakarta: Pustaka Grafitipers, 1987), Cet. 2. 183.

${ }^{8}$ Kata Pengantar Abdurrahman Wahid dan Hashim Wahid dalam Seyyed Hossein Nasr, Islam dalam Cita dan Fakta, (Yogyakarta: Pusaka, 2001), Cet. I. ix. 
Potret Kehidupan, Latar Belakang Pemikiran....

menyakini bahwa islam dengan wakat universal dan perenialnya mampu menjawab tantangan spiritual dunia modern. Masih dalam kerangka atau tipologi neo-modernisme, ia adalah pengkritik tajam Barat, sekaligus berusaha menggali dan membangkitkan warisan pemikiran Islam.

Lebih dari itu, Nasr dengan penuh semangat mengkritik tajam kaum modernis semacama Al-Afghani, Abbudh, Ahmad Khan atau Amir Ali. Bagi Nasr, tokoh-tokoh ini adalah pioner penyebaran sekularisme dalam bentuk rasionalisme dan berbagai kecenderungan apologetic lainya di dunia Muslim. Mereka adalah orang-orang yang mengecilkan atau bahkan menolak unsur-unsur ajaran Islam yang tidak "cocok" dengan pemikiran modern. Nasr mengecam keras orang seperti Amir Ali yang merasa malu atas konsepsi Islam tentang wanita, semata-mata karena tidak sesuai dengan konsep Barat. Bagi Nasr, penyebaran modernism hanya menimbulkan kebingungan dikalangan muslimin, yang pada giliranya mengakibatkan terjadinya jurang dan pemisahan yang semakin beasar antara berbagai bagian dunia islam.

Memandang kritiknya terhadap modernism dan tokoh-tokoh modernis itu dan mempertimbangkan warna pemikiranya, Nasr sangat boleh jadi merupakan pemikiran pasca-modernis. pasca-modernis Nasr, seperti tercermin dalam pemikirannya, mengambil bentuk kembali kepada islam "tradisional" dalam kerangka ini, orang tradisional adalah ia yang ingin memegangi "tradisi" yang suci, abadi, mempunyai kebijakkan yang perennial. Lebih terinci, orna gtradisional adalah ia yang menerima Al-Qur'an sebagai firman Tuhan, baik dalam isi maupun bentuk; yang menerima Kutub al-Sittah, keenam kumpulan hadits standar; ia yang memandang thariqah atau tasawuf sebagai dimensi batin atau jantung pewahyuan islam; ia yang percaya tentang islamisitas seni Isalam dalam hubungannya dengan dimensi batin Islam; dan ia yang dalam segi politik selalu bernagkat dari realism sesuai dengan norma-norma Islam.

Lebih dari itu, Nasr sangat mungkin pula dalah seorang "neo-sufi” yang menerima pluralism dan perennialisme dalam kehidupan keagamaan. Neo-Sufisme Nasr adalah tasawuf menekankan aktivisme; tasawuf yang tidak mengakibatkan pengalamannya 


\section{Titin Nur Hidayati}

mengundurkan diri dari kehidupan dunia, tetapi sebaliknya melakukan inner detachment untuk mencapai reallisasi spiritual yang lebih maksimal. ${ }^{9}$

\section{KIPRAH SEYYED HOSSEIN NASR DALAM PEMIKIRAN ISLAM}

Seyyed Hossein Nasr sebagai tokoh pemikir islam dengan bahasa kontemporer tanpa meninggalkan sisi tradisional itu sendiri, berusaha menghadapi dan memberikan jawaban terhadap pandangan orientalis yang banyak berpijak pada pemikiran modern seperti matrealisme, sciencitesme dan sebagainya.

Setelah memperoleh gelah Ph.D. dalam bidang sejarah sains dan filsafat Islam dari Harvard University, pada tahun 1958, Nasr kembali ke Iran. Di sini ia lebih mendalami filsafat Timur dan filsafat tradisional dengan banyak diskusi bersama para tokoh terkemuka agama Iran, seperti Thabathaba'I, Abu Hasan al-Qazwini, dan kazin Asar. Dalam kegiatan akademik, Nasr megnajar di Universitas Teheran, menjadi dekan falkultas sastra pada lebaga yang sama tahun 1968-1972, ${ }^{10}$ dan pada tahun 1962-1965 ia diangkat sebagai profesor tamu pada Harvard University. Ia juga sarjana sarjana yang menduduki pimpinan Aga Khan Chair of Islamic Studies yang baru dibentuk di American University of Beirut (1964-1965). ${ }^{11}$ Pada tahun 1975-1979 Nasr menjadi direktur Imperial Iranian Academy of Philosophy, sebuah lembaga yang didirikan dinasti Syah Reza Pahlevi, untuk memajukan pendidikan dan kajian filsafat. Nasr berhasil dalam tugas ini sehingga ia diberi gelar kebangsaan oleh Syah.

Kredibilitas Nasr sebagai intelektual dan akademisi tidak hanya di kenal di negaranya sendiri tetapi juga diakui di negeri lain. Sehingga sering di undang seminar atau memberi kuliah diluar negeri. Antara lain, memberi kuliah tamu di Hardvard, Amerika, tahun 1962-1965. Universitas Amerika di Beirut (Amerika University of Beirut) tahun 1964-1965. Menjadi direktur lembaga Aga Khan untuk kajian ke-Islaman (Aga Khan Chair Of Islamic Studies) pada Universitas yang sama. Nasr juga memberikan makalah pada Pakistan Philosofhical Congress, di Pakistan, tahun 1964; memberikan kuliah di Universitas Chicago, tahun 1966, atas sponsor Rockkefeller Foundation, dan tahun 1981

\footnotetext{
${ }^{9}$ Azyumardi Azra, Historiografi Islam Kontemporer, (Jakarta: Gramedia, 2002), Cet, I. 93-94.

${ }^{10}$ A. Khudori Soleh, Wacana Baru Filsafat Islam, (Yogyakarta: Pustaka Pelajar, 2004). Cet. I. 317.

${ }^{11}$ Ali Maksum, Tasawuf Sebagai Pembebasan Manusia Modern, 46.
} 
memberikan kulah di Giffort Lectures, lembaga yang didirikan oleh Universitas Edinburg (Edinburg University) tahun 1989. ${ }^{12}$

Selain itu, ia bersama Ayatullah Murtadha Muthahari (1919-1979) dan Ali Syari’ati (1933-1977), dan beberapa tokoh lain, pada akhir 1965 mendirikan Husainiyyah Irsyad, lembaga yang bertujuan mengembangkan ideologi Islam untuk generasi muda berdasarkan perspektif Syi'ah. Tetapi menjelang ditutupnya lembaga tersebut oleh Reji Shah pada tahun 1973, Nasr dan Mutahhari keluar dari lembaga ini, yang menurut mereka telah dikuasai 'Ali Syari'ati. Seorang modern muslim yang mengkritik keras ulama tradisonal. Keduanya memandang Syarti'ati sebagai orang yang telah menyalahgunakan lembaga ini untuk kepentingan politiknya sendiri. Nasr sangat kritis dengan syari'ati yang dipandang keliru menampilkan islam sebagai agama evolusioner dengan menghilangkan aspek spritualnya. ${ }^{13}$

Nasr pernah datang juga ke Indonesia, Juni 1993, atas undangan yayasan Wakaf Paramadina bekerja sama dengan penerbit Mizan. Di sini ia memberi tiga ceramah dengan topik berbeda, (1) tetang "seni Islam” sekaligus peluncuran buku Spiritual dan Seni Islam (Bandung, Mizan, 1993), (2) tetang "Spiritualitas, krisis dunia modern dan agama masa depan", (3) tentang "filsafat perennial". ${ }^{14}$

\section{KARYA-KARYA SEYYED HOSSEIN NASR}

Sebagai pemikir yang memproklamirkan diri sebagai seorang tradisionalis perlu kiranya dilihat konsistensinya. Dalam hal ini perlu kiranya dipaparkan alur pemikirannya agar terlihat peta pemikirannya yang menyeluruh dan komprehensif Untuk mengetahuinya perlu dipaparkan secara historis tahapan pemikiran yang telah dia lalui. Dengan demikian, untuk memudahkan pembahasan maka perlu dibagi periodesasi dari pemikiran Nasr. Setidaknya dapat kita bagi menjadi empat periode 1960-an, 1970-an, 1980-an dan 1990an. ${ }^{15}$ Pada periode ini pertama pemikiran Seyyed Hossein Nasr dapat dilihat pada karyanya yang pertama yaitu An Introduction to Islamic Cosmological Doctrines (1964). ${ }^{16}$

\footnotetext{
${ }^{12}$ A. Khudori Soleh, Wacana Baru Filsafat Islam, 317-318.

${ }^{13}$ Ali Maksum, Tasawuf Sebagai Pembebasan Manusia Modern, 47.

${ }^{14}$ A. Khudori Soleh, Wacana Baru Filsafat Islam, 318-319.

15 Pembagian periode ini sebagaimana merujuk periodesasi yang dibuat oleh Ali Maksum, Lihat Ali Maksum, Tasawuf Sebagai Pembebasan Manusia Modern, 56.

${ }^{16}$ Buku ini adalah Disertasi Doktoralnya yang dipertahankan pada tahun 1958 di Harvard University. Kemudian mulai dipublikasikan pada tahun 1964. Lihat Seyyed Hossein Nasr, An Introductiont to Islamic Cosmological Doctrines (Cambridge: Harvard University Press, 1964); Lihat juga Nidhal Guessoum, Islam's Falasifa, Vol. 10 Nomor 2 September 2019| 138
} 
Titin Nur Hidayati

Buku ini mengkaji tentang konsep kosmologi $^{17}$ tradisionalis yang memaparkan tentang pandangan-pandangan metafisis dari para pemikir klasik seperti Ihkwan alShafa', Ibn Sina dan al-Biruni. ${ }^{18}$ Pada tahun yang sama juga dipublikasikan karya Nasr yang berikutnya berjudul Three Muslim Sages (1964) yang memaparkan pemikiran tiga tokoh muslim klasik, yaitu Ibnu Sina dengan filsafat Paripatetiknya (masysyaiyyah).Suhrawardi dengan filsafat Illuminasionisme (isyraqiyyah), dan Ibn "Arabi dengan pemikiran 'Irfaniyahnya (ma'rifah). ${ }^{19}$

Selanjutnya Nasr menerbitkan karya yang fokus membicarakan Islam secara rinci yang banyak memaparkan sumber-sumber ajaran Islam dan cara memahaminya. Dipaparkan tentang urgensi Al-Qur'an sebagai wahyu sekaligus sumber pengetahuan, juga mengenai Hadits sebagai sumber ajaran kedua setelah Al-Qur'an. Penjelasannya lebih mendalam sampai bagaimana cara memahami keduanya melalui jalan spiritual yang dimulai dari Syari'ah, tariqat dan Haqiqiyah. Buku ini telah dipublikasikan dengan judul Ideals and Realisties and Islam (1966). Buku ini menguraikan secara terperinci tentang karakteristik Islam dan upaya menjadikan wahyu sebagai sumber inspirasi ilmu pengetahuan. Buku ini telah diterjemahkan dalam bahasa Indonesia oleh Abdurrahman Wahid dan Hasyim Wahid dengan judul Islam Antara Cita dan Fakta (2001). Buku ini sebenarnya adalah seri ceramah Nasr yang disajikan di American University of Beirut selama tahun akademik 1964-1965. ${ }^{20}$

Di akhir era 1960-an Nasr mulai melontarkan kritiknya terhadap Barat secara langsung. Mengenai kritiknya atas realitas kemanusiaan modern ia menulis karya berjudul Man and Nature: the Spiritual Crisis of Modern Man (1968). Buku ini banyak membicarakan krisis spiritual manusia modern Nasr menyebutkan salah satu bukti dari

Quantum Question Reconciling Muslim Tradition and Modern Science, (New York: Palgrave Macmillan, 2011), 166.

${ }^{17}$ Secara tradisional kosmologi dianggap sebagai cabang metafisika yang bergumul dengan pertanyaanpertanyaan mengenai asal dan susunan alam raya, penciptaan dan kekekalannya, vitalisme atau mekanisme, kodrat hukum, waktu, ruang dan kausalitas. Lihat: Loren Bagus, Kamus Filsafat, (Jakarta: Gramedia, 2000), 499.

${ }^{18}$ Seyyed Hossein Nasr, Spiritualitas, Krisis Dunia Modern dan Agama Masa Depan (Jakarta: Paramadina, 1993), 45-48.

${ }^{19}$ Ali Maksum, Tasawuf Sebagai Pembebasan Manusia Modern, 57; lihat juga bukunya: Abu Muhammad Iqbal, Pemikiran Pendidikan Islam, 345.

${ }^{20}$ Seyyed Hossein Nasr, Islam antara Cita dan Fakta, terj. Abdurrahman Wahid dan Hasim Wahid, (Yogyakarta: Pusaka, 2001), 152. 


\section{Potret Kehidupan, Latar Belakang Pemikiran....}

krisis ini adalah bahwa manusia modern telah memperlakukan alam sekitarnya dengan semena-mena. Hal ini sekaligus peringatan kepada negara berkembang yang telah terancam modernisasi dan globalisasi. Nasr menawarkan konsep Islam tentang fitrah manusia sebagai makhluk yang berketuhanan. Ia memperingatkan agar manusia menghormati alam semesta sebagai sesama makhluk Tuhan sekaligus tajalli dari-Nya. Hampir bersamaan dengan terbitnya karya di atas, ia juga memperkenalkan spirit sejarah sain tradisional kepada Barat yang meliputi konsep metafisika, filsafat dan agama dalam Islam. ${ }^{21}$ Karyanya ini diberi judul Science and Civilization in Islam (1968). Buku ini terdiri atas 13 bab diawali dengan mengetengahkan prinsip-prinsip Islam dan berbagai perspektif dalam peradaban Islam hingga tradisi ma'rifah. Buku ini diberi kata pengantar oleh George de Santilana, salah satu guru Nasr. Buku ini bertujuan untuk menyadarkan manusia muslim mengenai apa yang harus dibenahi dalam menyerap ilmu pengetahuan Barat dan memperkenalkan kepada pembaca-pembaca Barat tentang isi dan spirit sejarah sains islam dalam perspektif tradisional. Lewat buku ini Nasr juga memperkenalkan konsep-konsep agama, metafisika, dan filsafat dalam Islam. ${ }^{22}$

Kritik Nasr atas dunia modern dan segala hal yang ada didalamnya pada akhir 1960-an kemudian semakin dipertajam di era 1970-an. Ia banyak menawarkan alternatifalternatif keluar dari krisis modernitas ini dengan memperkenalkan tasawuf. Tasawuf merupakan bentuk kongkrit dari pemikirannya mengenai gnosisme, irfan, dan filsafat yang ia pelajari sejak awal. Keistimewaan tasawuf dipaparkan dengan sederhana dalam Bukunya Sufi Esseys (1972). Dalam buku ini, Nasr melakukan pengkajian yang cukup menyentuh dan lengkap tentang tasawuf dari akar sejarahnya serta memberikan alternatif kepada manusia bagaimana sufisme itu bisa dipraktekkan dalam dunia modern ini yang penuh dengan materi. ${ }^{23}$

Di akhir 1970-an ia kembali mempertajam kritiknya atas manusia modern dengan mengetengahkan buku yang profokatif dan penuh keprihatinan berjudul Islam and the Plight of Modern Man (1976). Buku ini berisi tentang masalah-masalah penting yang

\footnotetext{
${ }^{21}$ Ahmad Norma Permata, Tradisi dalam Perenialisme: Melacak Jejak Filsafat Abadi, (Yogyakarta Tiara Wacana, 1996), 89-91.

${ }^{22}$ Seyyed Hossein Nasr, Science and Civilization in Islam, terjemahan: J. Mahyudin, (Bandung: Pustaka, 1986), Cet. I, v-xii.

${ }^{23}$ Abu Muhammad Iqbal, Pemikiran Pendidikan Islam Gagasan-gagasan Besar Para Ilmuwan Muslim. (Yogyakarta: Pustaka Pelajar, 2015), 345.

Falasifa, Vol. 10 Nomor 2 September 2019| 140
} 


\section{Titin Nur Hidayati}

dihadapi oleh manusia modern. Buku ini juga membahas cara-cara penerapan ajaran warisan intelektual dan spiritual Islam. Selain itu juga alternatif besar ajaran Islam tersebut untuk mencari jalan keluar dari kedudukan manusia modern melalui penerapan ajaran Islam. $^{24}$ Di tahun 1976 juga terbit buku Islamic Science; an Illustrated Study. Buku ini berusaha menolak tuduhan bahwa Islam hanya mewarisi ilmu dan kebudayaan dari bangsabangsa sebelumnya tanpa memiliki originalitas. ${ }^{25}$

Memasuki era 1980-an Nasr tetap konsisten dengan basis pemikirannya. Ia banyak menuangkan gagasannya secara kongkrit sebagai alternatif hidup di dunia modern. Di awal 1980-an ia memualainya dengan menampilkan sejarah pemikiran Islam yang kian merosot di abad 19 dikarenakan pengaruh modernisasi Barat. Ia banyak mengkritik para muslim modernis yang dinilai sebagai pengemban pemikiran modern barat yang sekuler. Mereka dipetakan sebagai kaum rasionalis yang telah jauh meninggalkan dimensi batin Islam yang justru paling penting dalam keislaman itu sendiri. Sebagai contoh yang melakukan hal ini disebutkannya tokoh pemikir Mesir, Muhammad Abduh (w. 1905). Abduh misalnya menampilkan corak tafsir yang adabi ijtima'i yang banyak kontroversial. Selain itu dicontohkannya pula seperti Al-Afghani (w. 1897), Amir Ali (w. 1928) dan Ahmad Khan (w. 1989). Menurut Nasr, selain mereka ada gerakan-gerakan purotanis rasionalistik yang membunuh tasawuf seperti halnya gerakan Wahabiyah yang dituduh sebagai biang kemunduran umat Islam. Adapun buku yang menjelaskan hal ini berjudul Islamic Life and Thought (1981). Buku ini merupakan penjelasan tentang usaha untuk menjawab bahwa tasawuf bukanlah merupakan biang keladi (dijadikan kambing hitam) atas kekalahan Islam atas konfrontasi Barat, tetapi kehancuran umat Islam karena penghancuran tasawuf dan tarekat sufi oleh gerakan-gerakan rasionalisme puritan Islam. ${ }^{26}$

Pada tahun yang sama Nasr menerbitkan buku berjudul Knowledge and The Sacred (1981) yang merupakan kumpulan teks kuliahnya yang disampaikan dalam Gifford Lecture di University of Endinburg, yang diedit oleh Miss Kathleen O’brien. Ia banyak mendiskusikan sumber pengetahuan suci yang berisi pengetahuan tentang gnosisme. Dalam buku ini Nasr menjelaskan apa itu Islam Tradisional, dan bagaimana pertentangan

\footnotetext{
${ }^{24}$ Ibid, ${ }^{26}$ Ibid,

${ }^{25}$ Ibid,
} 


\section{Potret Kehidupan, Latar Belakang Pemikiran....}

dengan dunia modern. Buku ini banyak membahas tentang pengetahuan suci, Scientia sacra,dari berbagai titik pandang agama-agama. Dalam buku ini juga Nasr mengajak manusia untuk kembali menjelajah ke sumber-sumber ilmu pengetahuan yang dari Timur khususnya Islam. ${ }^{27}$ Dia banyak membicarakan epistemologi berpikir tradisional dalam Islam. Konsep intellectus di tampilkan sebagai sebuah kemampuan manusia yang tertinggi dalam usaha menyingkap dan mendapatkan pengetahuan suci ini. Bukti dari kemampuan ini adalah terciptanya seni suci dan seni tradisional oleh bangsa Persia sebagai pencapaian jiwa manusia tertinggi, sehingga dapat menyingkap realitas Keindahan Mutlak yang berada di balik dunia bentuk (form) dalam wilayah eksoterik. Penjelasan ini dituangkan pada bab 8 yang khusus membahas tentang seni tradisional sebagai sumber pengetahuan dan keanggunan.

Pada akhir 1980-an ia menulis buku berjudul Islamic of Art and Spirituality (1987) sebagai penjelasan lebih rinci dari bab 8 pada buku berjudul Knowledge and The Sacred (1981). Karya ini mengulas keindahan dan kebesaran seni budaya Persia sebagai seni suci dan seni tradisional. Menurutnya seni suci adalah seni yang berhubungan langsung dengan praktek-praktek utama agama dan kehidupan spiritual seperti seni kaligrafi dan seni baca Al-qur'an serta seni arsitektur bernuansa geometris: sedangkan seni tradisional adalah seni yang melukiskan prinsip-prinsip wahyu Islam dan spiritualitas tetapi dengan cara yang tidak langsung. ${ }^{28}$ Ia menjelaskan prinsip keindahan berdasarkan teori seni metafisis Platonian, yang memandang wujud universal dan ideal. Secara khusus ia menjelaskan tentang cara menghayati karya seni suci dan seni tradisional melalui metode pendakian jalan spiritualitas ( syari'ah, tariqat dan haqiqah ). Dengan kata lain buku ini berisi tentang seni Islam yang dihasilkan oleh para pemikir Islam itu berdasarkan gagasan tentang tauhid, yang menjadi inti dari wahyu Islam. Nasr menyatakan bahwa seni Islam memainkan peran penting dalam masyarakat manusia, suatu peran yang menbangkitkan dzikir dan tafakur tentang Tuhan.

Memasuki periode keempat, yaitu era 1990-an, Nasr menggagas tindakan nyata tentang teori-teori dan pendapatnya dengan lebih fokus mengarahkan pandangan sufistiknya menjadi praktis dalam kehidupan modern. Misalnya ia berpendapat mengenai

\footnotetext{
${ }^{27}$ Ibid,

${ }^{28}$ Seyyed Hossein Nasr, Spiritualitas dan Seni Islam. Terj. Sutejo, (Bandung: Mizan, 1993), 13-14.

Falasifa, Vol. 10 Nomor 2 September 2019| 142
} 


\section{Titin Nur Hidayati}

titik temu agama-agama yang ia tuangkan dalam Religion and Religion: The Challenge of Living in a Multireligious World (1991). Buku ini merupakan kelanjutan pemikiran Nasr sebelumnya dalam rangka mencari titik temu agama-agama di dunia. ${ }^{29}$

Kemudian ia juga menulis pengetahuan kesufian khusus untuk kaum muda berjudul A Young Muslim's Guide to the Modern World (1994). Buku ini memberikan bimbingan kepada generasi muda muslim dakam menjelajahi dunia modern, agar mampu memahami lebih dalam lagi tentang peradaban Barat dan pemikiran modern yang telah mempengaruhi dunia Islam selama kurang dua abad belakangan ini. Dalam buku ini Nasr memperkenalkan tentang warisan klasik sehingga dalam menghadapi dunia modern mampu memfilter dan tidak goyah keimanannya. ${ }^{30}$ Dan pada pertengahan dasa warsa ini bersama dengan Oliver Leaman mengedit karya-karya mengenai filsafat Islam menjadi sebuah buku berjudul History of Islamic Philosophy (1994) yang banyak menjelaskan perkembangan filsafat Islam mulai dari jaman klasik hingga jaman kontemporer sekarang ini.

Karya Nasr yang lainnya Living Sufism. Buku ini berisi beberapa persoalan masa kini yang dihadapi dunia modern pada umumnya dan dunia Islam pada khususnya yaitu persoalan yang penyelesainnya tergantung pada pemahaman dan pemakaian prinsipprinsip.

Shadr al-Din al Shirazi and His Transenden Theoshophy. Buku ini memperlihatkan karakteristik filsafat yang dikembangkan oleh philosof Muslim yang selalu bersumber pada wahyu. Dalam buku ini Nasr membahas tentang filsafat Mulla Shadra, tokoh yang di pandang Nasr sebagai fakta sejarah kesinambungan sejarah filsafat Islam pasca Ibn Rusd. Traditional Islam in the Modern Word. Buku ini menguraikan apa itu tradisional Islam dan dimana letak perbedaan dan pertentangannya tujuan pendidikan Islam bukan hanya pelatihan pikiran melainkan juga pelatihan seluruh wujud sang person. The Heart of Islam: Enduring Values for Humanity. Buku ini menjelaskan beberapa aspek

\footnotetext{
${ }^{29}$ Abu Muhammad Iqbal, Pemikiran Pendidikan Islam, 346.

${ }^{30}$ Ibid, 344-345.
}

Falasifa, Vol. 10 Nomor 2 September 2019| 143 
mendasr dari Islam dan upaya mendiskusikan isu-isu secara luas sesuai dengan pendapat mayoritas umat Islam yang dapat dipahami oleh masyarakat Barat. ${ }^{31}$

Dengan demikian karya-karya Seyyed Hossein Nasr antara lain:

1. An Introduction to Islamic Cosmological Doctrines (1964)

2. Three Muslim Sages (1964)

3. Ideals and Realisties and Islam (1966).

4. Man and Nature: the Spiritual Crisis of Modern Man (1968).

5. Science and Civilization in Islam (1968).

6. Sufi Esseys (1972).

7. Islam and the Plight of Modern Man (1976).

8. Islamic Science; an Illustrated Study (1976).

9. Islamic Life and Thought (1981).

10. Knowledge and The Sacred (1981)

11. Islamic of Art and Spirituality (1987)

12. Religion and Religion: The Chlallenge of Living in a Multireligious World (1991).

13. A Young Muslim's Guide to the Modern World (1994).

14. History of Islamic Philosophy (1994)

15. Living Sufism.

16. Shadr al-Din al Shirazi and His Transenden Theoshophy.

17. Traditional Islam in the Modern Word.

18. The Heart of Islam: Enduring Values for Humanity.

Husein Nasr sedikitnya telah menghasilkan sekitar 50 buku. ${ }^{32}$ Selain itu Nasr juga menulis sekitar 500 artikel untuk seminar dan jurnal ilmiah di berbagai negara antara lain: Journal Milla wa Milla (Melbourne, Australia), Journal Iran (terbit di London), Studies in Comparative religion (London, Inggris), Religion Studies (Cambridge, Inggris), The Islamic Quartely (London, Inggris), Hamdard Islamicus dan Word Spirituality. ${ }^{33}$

31 Ali Maksum, Tasawuf Sebagai Pembebasan Manusia Modern, hlm56-64. Lihat Juga: Abu Muhammad Iqbal, Pemikiran Pendidikan Islam, 344-346.

${ }^{32}$ A. Khudori Soleh, Filsafat Islam Dari Klasik Hingga Kontemporer, (Yogyakarta: Ar-Ruzz Media, 2013), 367.

${ }^{33}$ Husein Nasr, Sufi Essays (New York: University of New York Press, 1972), hlm. 21. Dalam A. Khudori Soleh, Filsafat Islam ...hlm. 368.

Falasifa, Vol. 10 Nomor 2 September 2019| 144 
Titin Nur Hidayati

\section{KESIMPULAN}

Seyyed Hossein Nasr merupakan salah satu juru bicara Islam di Barat yang gigih menyuarakan pemikiran Tradisionalisme untuk membentengi arus modernisasi yang telah merusak sendi-sendi tradisi luhur masyarakat khususnya Islam. Sekularisasi seni saat ini juga dirasakan masyarakat Indonesia dengan berbagai fenomena bahwa seni tidak lagi mempunyai pesan dari Dunia atas, melainkan hanya sebagai bahan hiburan yang temporal dan terkadang sebagai barang dagangan murahan tanpa memperhatikan tujuan seni sebagai medium antara materialisme dunia dan kerohanian yang kekal.

\section{DAFTAR PUSTAKA}

al-Baghdadi, Abdurrahman. 2004. Seni Dalam Pandangan Islam: Seni Vokal, Musik dan Tari. Jakarta: Gema Insani Press.

Al-Ghazali. 1993. Kimia Kebahagiaan, Terj. Tim Mizan. Bandung: Mizan. 1980. Ihya Ulum al-Din. Juz, I, II, III, IV. Beirut: Dar al-Fikr.

Azra, Azyumardi. 2002. Historiografi Islam Kontemporer. Jakarta: Gramedia

Bagus, Loren. 2000. Kamus Filsafat. Jakarta: Gramedia.

Guessoum, Nidhal. 2011. Islam's Quantum Question Reconciling Muslim Tradition and Modern Science. New York: Palgrave Macmillan.

Hasan, Zainul. 2004. Islam Tradisional; Kajian atas Pemikiran Nasr. Pamekasan: Journal Studi Keislaman, Vol. V No. 1 STAIN.

Hidayat, Komaruddin. 1987. Upaya Pembebasan Manusia Sufistik Terhadap Manusia Modern Menurut Seyyed Hossein Nasr, dalam Insan Kamil: Konsep Manusia Menurut Islam, Penyunting: M. Dawam Rahardjo. Jakarta: Pustaka Grafitipers.

Iqbal, Abu Muhammad. 2015. Pemikiran Pendidikan Islam Gagasan-gagasan Besar Para Ilmuwan Muslim. Yogyakarta: Pustaka Pelajar.

Jakob. 2000. Filsafat Seni. Bandung: Penerbit ITB.

Maksum, Ali. 2003. Tasawuf Sebagai Pembebasan Manusia Modern: Telaah Signifikansi Konsep Tradisionalisme Seyyed Hossein Nasr. Yogyakarta: Pustaka Pelajar. 
Potret Kehidupan, Latar Belakang Pemikiran....

Nashir, Haedar. 1999. Agama dan Krisis Kemanusiaan Modern. Yogyakarta: Pustaka Pelajar.

Nasr, Seyyed Hossein. 2001. Islam antara Cita dan Fakta, terj. Abdurrahman Wahid dan Hasim Wahid. Yogyakarta: Pusaka.

. 1964. An Introductiont to Islamic Cosmological Doctrines. Cambridge: Harvard University Press.

- 1993. Spiritualitas, Krisis Dunia Modern dan Agama Masa Depan. Jakarta: Paramadina.

. 1986. Science and Civilization in Islam, terjemahan: J. Mahyudin. Bandung: Pustaka.

Yogyakarta: Pustaka Sufi.

. 2003. Sufisme Persia Awal, terj. Gafna Raiz Wahyudi,. 1993. Spiritualitas dan Seni Islam. Terj. Sutejo. Bandung: Mizan.

1972. Sufi Essays. New York: University of New York Press.

. 1996. Tentang Tradisi dalam Perenialisme: Melacak Jejak Filsafat Abadi, (ed.) Ahmad Norma Permata. Yogyakarta: Tiara Wacana.

. 2004. Intelegensi dan Spiritualitas Agama-agama. Terj. Suharsono dkk. Jakarta: Inisiasi Press.

1994. Islam Tradisi di Kancah Dunia Modern, Terj. Lukman Hakim. Bandung: Pustaka.

Bandung: Mizan.

2003. The Heart of Islam, Terj. Nurasiah Fatih Sutan Harap.

Soleh, A. Khudori. 2004. Wacana Baru Filsafat Islam. Yogyakarta: Pustaka Pelajar.

2013.Filsafat Islam Dari Klasik Hingga Kontemporer, Yogyakarta: ArRuzz Media.

Usman, Ali. 2006. Kebebasan adalah Nyawa Manusia: Menapaki Jejak-Jejak Pemikiran Jean Paul Sartre, Kebebasan dalam Perbincangan Filsafat, Pendidikan dan Agama. Yogyakarta: BEM AF UIN SUKA dan Pilar Media. 
Titin Nur Hidayati

Falasifa, Vol. 10 Nomor 2 September 2019| 147 